M. Tsizh, postgrad. stud.,

B. Novosyadlyj, Dr. Sci., prof.

Ivan Franko National University of Lviv, Lviv

\title{
FORMATION OF THE SPHERICAL VOIDS IN THE MODELS OF THE UNIVERSE WITH DARK ENERGY
}

We analyze evolution of cosmological perturbations which lead to the formation of large voids in the distribution of galaxies. We suppose that perturbations are spherical and main energetic components - radiation, matter and dark energy - are continuous media with ideal fluid energy-momentum tensors, which interact only gravitationally. Equations of the evolution of perturbations in the comoving to cosmological background reference frame for every component are obtained from equations of conservation and Einstein's ones and are integrated by modified Euler method with setting the initial conditions at the early stage of evolution in radiation-dominated epoch, when the scale of perturbation is mush larger than particle horizon. Obtained results illustrate dynamics of dark energy in the void region and its dependence on parameter of effective speed of sound of dark energy.

Key words: dynamical dark energy, cosmic voids, cosmological perturbations.

Удк 524.1-52, 524.1-65

Р. Гнатик, асп.,

В. Жданов, д-р фріз.-мат. наук, проф. КНУ імені Тараса Шевченка, Київ

\section{ПОШУК ГАЛАКТИЧНИХ ДЖЕРЕЛ ТРИПЛЕТУ КОСМІЧНИХ ПРОМЕНІВ 3 ЕНЕРГІЯМИ ПОНАД $10^{20}$ eB}

Серед зареєстрованих космічних променів гранично високих енереій (КПГВЕ, E>10 ${ }^{20}$ еВ) виділяється триплет подій в крузі радіуса $4^{0}$ в області Галактичного центру. Із застосуванням методу зворотнього розрахунку траєкторій КПГВЕ в магнітному полі Галактики показано, що потенційними галактичними джерелами триплету можуть бути мікроквазари SS433, GRS1915+105, магнетар SGR1900+14 та кулясте зоряне скупчення NGC6760.

Ключові слова: космічні промені, магнітні поля, мікроквазари, магнетари, кулясті скупчення.

Вступ. Космічні промені (КП) гранично високих енергій з енергіями $E>10^{20}$ eB - надзвичайно рідкісні явища: два найбільші детектори сучасності зареєстрували тільки відповідно 6 (детектор Pierre Auger Observatory (PAO, AUGER)) та 10 (детектор Telescope Array (TA)) таких подій [1, 2]. Потенційними джерелами КПГВЕ вважаються активні ядра галактик (АЯГ), космологічні гама-спалахи, припливні руйнування зір в околі надмасивних чорних дір, новонароджені мілісекундні пульсари та магнетарні спалахи [12]. Від перших трьох класів об'єктів очікується потік легких ядер протонів та гелію (заряд $Z=1,2$ ), тоді як від нейтронних зір із залізною корою можна очікувати також ядра заліза (заряд $Z=26)$ та продукти їх розпаду, зокрема, групу C-N-O (Z = 6-8). Спостережувана ізотропія КП надвисоких енергій $E>10^{18}$ еВ свідчить про їх суттєве відхилення в Галактичних та міжгалактичних магнітних полях $[1,2]$. Тому наявність триплету КПГВЕ - трьох подій в крузі радіуса $4^{0}$ в околі Галактичного центру (Галактичні координати триплету $I=35^{\circ}, b=-4^{0}$ ) [14] може свідчити про наявність Галактичного джерела КПГВЕ, оскільки в напрямку на триплет наша Галактика межує з гігантським (біля 60 Мпк) войдом, в якому практично немає АЯГ [17], тоді як для позагалактичних джерел КП з енергіями понад $10^{20}$ еВ ГЗК-горизонт (різке падіння потоку КП внаслідок їхньої взаємодії з реліктовим фоном) становить 75 Мпк [5]. Тому в нашій роботі відтворені траєкторії триплетних КПГВЕ в магнітному полі нашої Галактики та виділено об'єкти, які могли б бути джерелами цих подій.

Таблиця 1.Триплет подій

\begin{tabular}{|l|l|c|c|c|c|}
\hline № & Експеримент & Рік & $\boldsymbol{E}(\boldsymbol{E e V})\left(\boldsymbol{E}_{\text {cal }}(\mathrm{EeV})\right)$ & $\boldsymbol{I}\left(^{\circ}\right)$ & $\boldsymbol{b}\left(^{\circ}\right)$ \\
\hline 1 & AUGER & 2008 & 118,3 & 36,50 & $-3,60$ \\
2 & Telescope Array & 2011 & $135,50(117,9)$ & 35,72 & $-4,68$ \\
3 & Telescope Array & 2008 & $101,40(88,2)$ & 32,74 & $-3,33$ \\
\hline
\end{tabular}

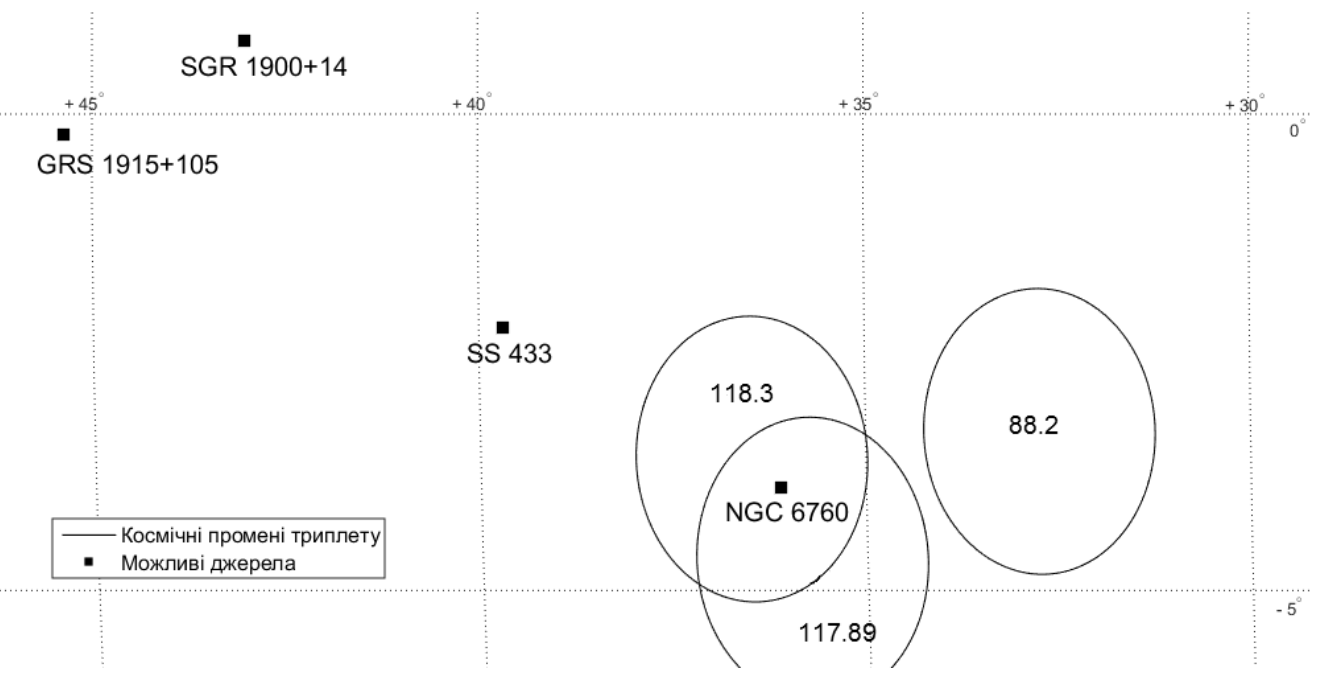

Рис. 1. Триплет подій та його потенційні джерела. Кожен КП позначений кружком, розмір якого відповідає інструментальній похибці (роздільній здатності) детектора, із вказанням енергії КП в ЕеВ 
Характеристики триплету КПГВЕ. Як вже відмічалось вище, серед 16 подій з енергіями понад 1020 еВ, зафріксованими детекторами РАО та ТА, три утворюють триплет діаметром до $4^{0}$, який може свідчити про наявність одного джерела цих подій $[14,15]$. Характеристики подій триплету приведені в табл. 1 а його положення на небі - на рис. 1. Важливо відмітити, що роздільна здатність (похибка вимірювання) координат подій в РАО (TA) рівна $0.9^{0}\left(1.5^{0}\right)$, а статистична похибка вимірювання енергії РАО (TA) рівна $12 \%$ (20\%). Для узгодження спостережуваних потоків КПНВЕ в експериментах РАО та ТА команда ТА в 2015 р. ввела калібрування (пониження) енергії своїх подій на $13 \%: \mathrm{E}_{\text {cal }}=0.87 \mathrm{E}[16]$, що враховано в табл. 1.

Галактичне магнітне поле. Галактичне магнітне поле моделюється сумою регулярного та випадкового компонентів [7, 10, 11]. Регулярне магнітне поле складається із дискового поля із спіральною структурою, яка відповідає структурі спіральних рукавів, із тороїдального поля гало Галактики та із X-подібного осесиметричного полоїдального поля, направленого від південної до північної півкулі Галактики [10]. Оцінки показують, що для напрямку на триплет $l=35^{0}, b=-4^{0}$ на відстанях до 10-12 кпк КП рухаються головним чином вздовж рукава і поперечний компонент поля диску малий, так що відхилення траєкторії КП визначається значенням $X$ - поля в диску:

$$
B_{z}(r)=B_{x} \exp \left(-r / r_{x}\right) \text {, }
$$

де $\boldsymbol{r}$ - радіус-вектор КП відносно центра Галактики, $B_{X}=4.6 \pm 0.3 \mu Г \mathrm{c}, r_{X}=2.9 \pm 0.1$ кпк [10].

Траєкторія КП з енергією Е та зарядом $q=e Z$ в магнітному полі В описується рівняннями руху для радіус-вектора КП $\boldsymbol{r}$ та швидкості $\mathbf{v}$ (для КПГВЕ Лоренц-фактор $\gamma \approx 1 \mathrm{i}|\mathbf{v}| \approx c$ ):

$$
\frac{d \mathbf{r}}{d t}=\mathbf{v} ; \frac{d \mathbf{v}}{d t}=\frac{q c^{2}}{E}[\mathbf{v} \times \mathbf{B}]
$$

Обчислення траєкторії КП здійснюється методом зворотнього розрахунку: з положення спостерігача (Сонця) в Галактиці в прямокутних координатах ( $x=-8.5$ кпк, $y=0, z=0)$ відносно центру Галактики запускається КП з тією ж енергією $\mathrm{E}$, але з зарядом -q в напрямку приходу спостережуваного КПГВЕ, який відтворить траєкторію задетектованого КП. Результати відтворення траєкторії для подій триплету приведені на рис. 2. та рис. 3. При цьому слід взяти до уваги, що похибки визначення напрямків приходу КПГВЕ, вплив випадкового компонента Галактичного магнітного поля та рівень достовірності прийнятої моделі Галактичного магнітного поля не дозволяють відтворити траєкторію КПГВЕ з точністю, кращою за 3-4 градуси $[1,2,7,10,11]$.

Таблиця 2. Можливі джерела триплету

\begin{tabular}{|c|l|c|c|c|c|}
\hline № & \multicolumn{1}{|c|}{ Ім'я } & Тип & ,, град & $\boldsymbol{b}$, град & $\boldsymbol{d}$, кпк \\
\hline 1 & GRS 1915+105 & Мікроквазар & 45,37 & $-0,22$ & $8,6_{-1,6}^{+2,0}$ \\
\hline 2 & SS 433 & Мікроквазар & 39,69 & $-2,24$ & $5,5 \pm 0,2$ \\
\hline 3 & NGC 6760 & Кулясте скупчення & 36,11 & $-3,9$ & $7,4 \pm 0,4$ \\
\hline 4 & SGR 1900+14 & Магнетар & 43,02 & 0,77 & $12,5 \pm 1,7$ \\
\hline
\end{tabular}

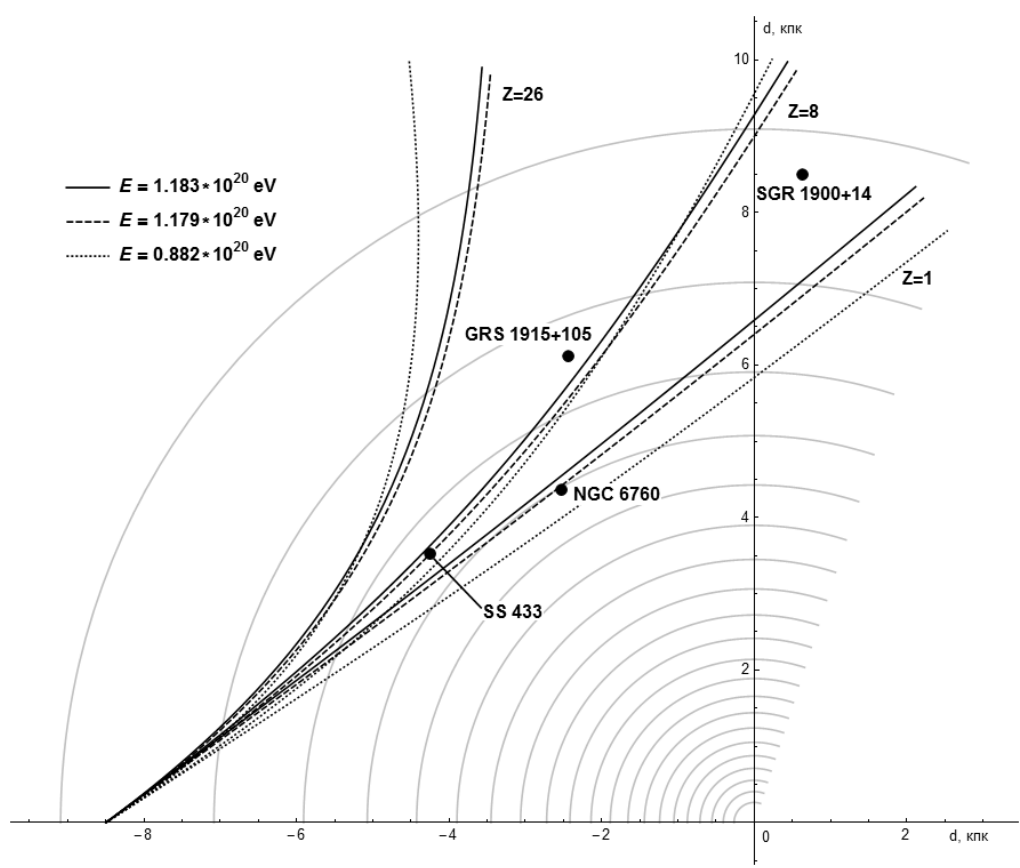

Рис. 2. Траєкторії космічних променів триплету в площині Галактики (х,y) для трьох значень заряду: $Z=1,8,26$. Центр Галактики відповідає координатам $(0,0)$, Сонце знаходиться в точці $(-8.5$ кпк, 0$)$.

Концентричні кола - ізолінії Z-компоненти магнітного X-поля 3 мінімальним значенням та 3 кроком 0.2 Гс

Обговорення та висновки. 3 рис. 2 випливає, що КП триплету при русі від своїх Галактичних джерел відхиляються магнітним полем в бік зменшення Галактичної широти I, причому величина відхилення суттєво залежить від заряду КП. Серед потенційних джерел вздовж траєкторії КП триплету (рис. 2, рис. 3) виділяються мікроквазари 
SS433 та GRS1915+105, прискорення КП в яких можливе в околі чорних дір сонячних мас чи в релятивістських струменях, хоча механізму прискорення до суб-ЗеВних енергій тут немає [12]. При спалахах Наднових можуть народжуватись магнетари - нейтронні зорі із гігантськими магнітними полями порядку $10^{15}$ Гс, які зараз проявляються як аномальні рентгенівські пульсари (Anomalous X-ray pulsars (AXPs)) чи як джерела повторних спалахів в м'якому гама-діапазоні (soft gamma repeaters (SGRs)) [6, 8, 12]. Магнетар SGR 1900+14 [13] виявляє спалахову активність, як вважається, внаслідок перезамикання магнітних полів в магнітосфрері, однак і тут максимальні енергії КП очікуються меншими, ніж в триплеті. Однак важливим позитивним моментом, особливо в магнетарній моделі, $є$ те, що потрібний заряд КП Z = 6-8 відповідає спостережним даним детектора AUGER щодо домінування проміжних ядер в хімічному вмісті КП суб-ЗеВних енергій [3, 4]. Кулясте зоряне скупчення NGC6760 виявляється потенційним джерелом для протон-гелієвих КП, які могли б бути прискореними в процесі припливного руйнування зорі в полі гіпотетичної чорної діри проміжної маси $\left(10^{3}-10^{4}\right.$ мас Сонця) в центрі скупчення [9] (чорні діри проміжних мас в центрах кулястих скупчень передбачаються і ведеться їх пошук, однак даних про наявність чорної діри в NGC6760 немає.)

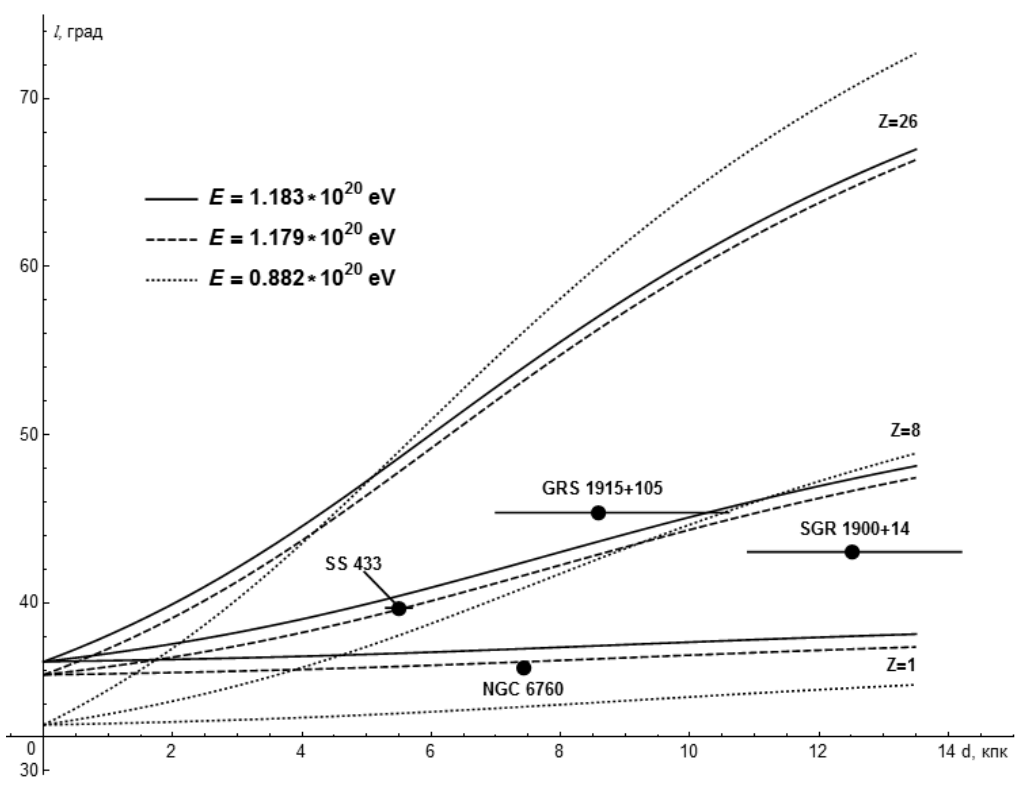

Рис. 3. Залежність галактичної довготи космічних променів триплету в залежності від пройденої відстані для трьох значень заряду: $Z=1,8,26$. Для потенційних джерел зображено похибку вимірювання відстані

Важливим моментом для інтерпретації даних спостережень триплету є транзієнтна природа прискорення КПГВЕ в потенційних галактичних джерелах: прискорення відбувається під час спалахової активності джерел - чи внаслідок вибухоподібної активності (зростання потужності релятивістсього струменя чи викид замагнічених плазмоїдів в мікроквазарах, магнетарний магнітосферний спалах), чи внаслідок утворення короткотривалого релятивістського струменя при припливному руйнуванні зорі в полі чорної діри [12]. Така активність джерел повинна супроводжуватись спалахами випромінювання в різних діапазонах електромагнітного спектру (з поправкою на час затримки приходу КПГВЕ відносно приходу фотонів внаслідок збільшення довжини траєкторії при відхиленнях в магнітному полі, який у нашому випадку становить десятки-сотні років). Тому важливо мати всехвильові спостереження потенційних кандидатів для додаткового підтвердження активності джерел в потрібний час. Зокрема, для магнетара SGR 1900+14 час затримки складає біля 30 років, що добре узгоджується із дуже яскравим спалахом магнетара SGR 1900+14 27 серпня 1998 року.

Мала статистика зареєстрованих КПГВЕ, недосконалість моделей Галактичного магнітного поля, локальні неоднорідності розподілу магнітного поля в околі Сонця затрудняють пошук Галактичних та позагалактичних джерел КПГВЕ, однак використання КП найвищих спостережуваних енергій для пошуку джерел залишається найперспективнішим напрямком, оскільки КПГВЕ зазнають найменших відхилень в магнітних полях, їх джерела повинні буди достатньо близькими (до 50-70 Мпк), а супроводжуючі їх прискорення нестаціонарні процеси - достатньо яскравими в електромагнітному випромінюванні. Тому покращення статистики КПГВЕ найближчим часом, зокрема, із введенням в дію орбітального детектора JEM-EUSO, дозволяє сподіватись на вирішення проблеми джерел КПГВЕ.

Подяки. Публікація містить результати досліджень, проведених при грантовій підтримці Державного фонду фундаментальних досліджень за конкурсним проектом Ф64/45-2016.

Список використаних джерел

1. Aab A., Abreu P., Aglietta M. et al. Searches for Anisotropies in the Arrival Directions of the Highest Energy Cosmic Rays Detected by the Pierre Auger Observatory // Astrophys. J.-2015. - 804. - P. 15.

2. Aab A., Abreu P., Aglietta M. et al. Searches for Large-Scale Anisotropy in the Arrival Directions of Cosmic Rays Detected above Energy of $10^{19} \mathrm{eV}$ at the Pierre Auger Observatory and the Telescope Array // Astrophys. J.-2014.-794, N 2.-P. 172.

3. Abbasi R., Bellido J., Belz J. et al. Report of the Working Group on the Composition of Ultra High Energy Cosmic Rays // arXiv:1503.07540 [astroph.HE]. -2014

4. Abbasi R.U., Abe M., Abu-Zayyad T. et al. Indications of Intermediate-Scale Anisotropy of Cosmic Rays with Energy Greater Than 57 EeV in the Northern Sky Measured with the Surface Detector of the Telescope Array Experiment // Astrophys. J. - 2014. - 790, N 2. - P. L 21.

5. Allard D. Extragalactic propagation of ultrahigh energy cosmic-rays // Astropart. Phys. - 2012. - 39-40, N 1. - P. 33-43.

6. Duncan R.C., Thompson C. Formation of very strongly magnetized neutron stars - Implications for gamma-ray bursts // Astrophys. J.-1992.-392, N 1. -P. L9-L13. 
7. Durrer R., Neronov A. Cosmological magnetic fields: their generation, evolution and observation // Astron. and Astrophys. Rev. - 2013. - 21.- P. 62.

8. Eichler D. Ultrahigh Energy Activity in Giant Magnetar Outbursts // arXiv:astro-ph/0504452. - 2005.

9. Farrar G.R., Piran T. Tidal disruption jets as the source of Ultra-High Energy Cosmic Rays // arXiv:1411.0704v1 [astro-ph.HE]. - 2014.

10. Jansson R., Farrar G.R. The galactic magnetic field // Astrophys. J. - 2012. - 761, N 1. - P. L11.

11. Jansson R., Farrar G.R. A New Model of the Galactic Magnetic Field // Astrophys. J.- 2012. - 757, N 1. - P. 14

12. Kotera K., Olinto A. V. The Astrophysics of Ultrahigh Energy Cosmic Rays // Ann. Rev. of Astron. and Astrophys. - 2011. - 49. - P. 119-153.

13. Olausen S. A., Kaspi V.M. The McGill Magnetar Catalog // Astrophys. J. Suppl. Ser. - 2014. - 212, N 1. - P. 6.

14. Sokolsky P. Recent Results from TA // Report on workshop "Multimessenger Astronomy in the Era of PeV Neutrinos." - 2014

15. Troitsky S.V. Doublet of cosmic-ray events with primary energies $>10^{20} \mathrm{eV} / / \mathrm{J}$. of Experiment. and Theor. Phys. Lett. - 2012. - 96, N 1. - P. 13-16.

16. The IceCube, Pierre Auger and Telescope Array Collaborations. Search for correlations between the arrival directions of IceCube neutrino events and ultrahigh-energy cosmic rays detected by the Pierre Auger Observatory and the Telescope Array // arXiv:1511.09408 [astro-ph.HE], - 2015 .

17. Tully R.B., Fisher J.R. Nearby galaxies Atlas // Cambridge: University Press. - 1987.

Надійшла до редколегії 01.02.16

Р. Гнатык, асп.,

В. Жданов, д-р физ.-мат. наук, профр.

КнУ имени Тараса Шевченко, Киев

\section{ПОИСК ГАЛАКТИЧЕСКИХ ИСТОЧНИКОВ ТРИПЛЕТА КОСМИЧЕСКИХ ЛУЧЕЙ С ЭНЕРГИЯМИ СВЫШЕ $10^{20}$ эВ}

Среди зарегистрированных космических лучей предельно высоких энергий (КЛПВЭ, E> $10^{20}$ эВ) выделяется триплет событий в круге радиуса $4^{0}$ в области Галактического центра. С применением метода обратного рассчета траекторий кЛПВЭ в магнитном поле Галактики показано, что потенциальнымu Галактическимu uсточникамu триплета могуm быть мuкроквазары SS433, GRS1915+105, магнетар SGR1900+14 и шаровое звездное скопление NGC6760.

Ключевые слова: космические лучи, магнитные поля, микроквазары, магнетары, шаровые скопления.

R. Gnatyk, postgrad. stud.

V. Zhdanov, Dr. Sci., prof.

Taras Shevchenko National University of Kyiv, Kyiv

\section{SEARCH OF THE GALACTIC SOURCES OF THE COSMIC RAY TRIPLET WITH ENERGIES ABOVE $10^{20} \mathrm{eV}$}

Among the registered extremely high energy cosmic rays (EHECR, E $>10^{20} \mathrm{eV}$ ) there is a triplet of events in a circle with radius of $4^{0}$ in the Galactic center region. With the use of the backtracking method for the calculation of EHECR trajectories in the Galactic magnetic it is shown that potential sources of galactic triplet can be microquasars SS433, GRS1915+105, magnetar SGR1900+14 and globular star cluster NGC6760.

Key words: cosmic rays, magnetic fields, microquasars, magnetars, globular clusters.

УдК 530.12

С. Парновський, д-р фіз.-мат. наук Астрономічна обсерваторія Киівського національного університету імені Тараса Шевченка

\section{МЕТРИКА ОДНОРІДНОЇ КОСМОЛОГІЧНОЇ МОДЕЛІ ТИПУ І ЗА БІАНКІ 3 ДОВІЛЬНИМ РІВНЯННЯМ СТАНУ МАТЕРІї}

Знайдена метрика однорідної космологічної моделі типа І за Біанкі з довільним рівнянням стану матерії, що заповнює Всесвіm.

При розгляді космологічних моделей значну уваги привертають однорідні космологічні моделі. Вони простіші, бо замість часткових похідних в рівняннях Ейнштейна залишаються звичайні. Крім того Всесвіт на великих масштабах $\epsilon$ досить однорідним, тому доцільно описувати його саме однорідними моделями. Частіше за все застосовують однорідні та ізотропні моделі, але інтерес мають також анізотропні моделі, що описуються класифрікацією за типами Біанкі [3]. Простіша з них це модель типу I за Біанкі, що має нульовий тензор просторової кривини. Знайдемо метрику такого простору-часу, що є заповнений однорідною матерією з довільним рівнянням стану $P(\rho)$, де $P-$ тиск, а $\rho-$ густина матерії. Цей випадок є цікавим не тільки тому, що він $є$ найбільш загальним, але і тому, що нам невідоме рівняння стану темної енергії, тому при дослідженнях сингулярностей ми маємо розглядати саме загальний випадок. Наприкінці ми покажемо, що отримана метрика переходить в деякі відомі точні розв'язки рівнянь Ейнштейна.

Метрику шукаємо у вигляді

$$
d s^{2}=d t^{2}-e^{2 \alpha(t)} d x^{2}-e^{2 \beta(t)} d y^{2}-e^{2 \gamma(t)} d z^{2} .
$$

Сигнатура простору-часу, знаки та позначення такі самі, як у відомому курсі Ландау та Ліфшица [3]. Використовуємо систему одиниць, в яких гравітаційна стала та швидкість світла дорівнюють одиниці. Тому густина матерії $\rho$ співпадатиме з густино. енергії. Рівняння Ейнштейна набувають вигляду:

$$
\begin{gathered}
-R_{1}^{1}=\ddot{\alpha}+\dot{\alpha}(\dot{\alpha}+\dot{\beta}+\dot{\gamma})=4 \pi(\rho-P), \\
-R_{2}^{2}=\ddot{\beta}+\dot{\beta}(\dot{\alpha}+\dot{\beta}+\dot{\gamma})=4 \pi(\rho-P), \\
-R_{3}^{3}=\ddot{\gamma}+\dot{\gamma}(\dot{\alpha}+\dot{\beta}+\dot{\gamma})=4 \pi(\rho-P), \\
-R_{0}^{0}=\ddot{\alpha}+\ddot{\beta}+\ddot{\gamma}+\dot{\alpha}^{2}+\dot{\beta}^{2}+\dot{\gamma}^{2}=-4 \pi(\rho+3 P),
\end{gathered}
$$

де крапка зверху позначає похідну за космологічним часом $t$. Введемо позначення

$$
3 f=\alpha+\beta+\gamma .
$$

